\title{
Type and token frequencies of phonological units in Hong Kong Cantonese
}

\author{
MAN-TAK LEUNG and SAM-PO LAW \\ University of Hong Kong, Hong Kong \\ and \\ SUK-YEE FUNG \\ Hong Kong Polytechnic University, Hong Kong
}

\begin{abstract}
This article reports, for the first time, type and token frequencies of tones, onsets, codas, rimes, and syllables of Hong Kong Cantonese. The information is derived from a computerized spoken corpus, the Hong Kong Cantonese adult language corpus (HKCAC; Leung \& Law, 2001), consisting of more than 140,000 character-syllable units. Since the HKCAC is based on recordings of connected speech, comparisons are made with respect to the inventories of various phonological units between the HKCAC and standard descriptions of the Cantonese phonological system-in particular, Fok (1974) and Bauer and Benedict (1997). It is hoped that the frequency information presented here will become a valuable tool for future psycholinguistic and linguistic research in this language. The full set of these frequency counts may be downloaded from the Psychonomic Society Web archive at www.psychonomic.org/ archive/.
\end{abstract}

In psycholinguistic research, it has been clearly shown that word frequency is an important factor influencing language processing. As such, frequency counts of words (based mostly on printed materials) have been extremely valuable in developing stimuli for experiments with various paradigms. Similarly, frequencies of occurrence of other linguistic units, such as the phoneme, may also play a significant role in certain areas of linguistic processing. In child language acquisition, phonological developmentin particular, the sequence of acquisition of phonemesmay be related to the frequencies of different phonemes in the language. Beyond normal language production, phoneme frequency may help explain neurolinguistic data. For example, the pattern of error production of brain-damaged patients with phonological paraphasias can be better understood if phoneme frequency is taken into consideration (e.g., Robson, Pring, Marshall, \& Chiat, 2003; Zangwill, 1975). The information may likewise be useful in interpreting perceptual judgments of the spoken output of individuals with motor speech disorders - that is, whether identification of phones produced by these patients is somehow biased toward phonemes with higher frequencies. Despite the potential use of phoneme frequency in studies of the language recognition and production of normal individuals, as well as those with speech/language deficits, one

The development of the HKCAC was made possible by a grant from the Research Grant Council of Hong Kong (HKU 5190/98H) from the Research Grant Council of Hong Kong. Address correspondence to S.-P. Law, Division of Speech and Hearing Sciences, University of Hong Kong, Pokfulam Road, Hong Kong SAR (e-mail: splaw@hkucc. hku.hk). is far less likely to find frequency counts of phonemes, when compared with word frequency counts, for most languages. In this article, we report frequencies of occurrence of onsets, codas, tones, rimes, and syllables in Hong Kong Cantonese, ${ }^{1}$ which is a widely spoken dialect in southeast China. It is hoped that the information will become a useful tool for various kinds of research concerning the language, be it psychological, linguistic, neurolinguistic, sociolinguistic, comparative studies, and so forth. We further emphasize its significance given the fact that it is extracted from a carefully transcribed spoken Cantonese database, the Hong Kong Cantonese adult language corpus (HKCAC; Leung \& Law, 2001). It is believed that phoneme frequency obtained from spoken materials more accurately reflects the occurrence of phonemes in a language than does that from phonetic transcription of a written corpus.

\section{Existing Spoken Chinese Corpora}

A rather extensive review of recent progress in the development of Chinese databases can be found in Wang (2001). Table 1 lists the major spoken corpora in Mandarin, Cantonese, and Shanghainese described in Wang and in Leung and Law (2001). The list indicates that most of the spoken databases are of adult language. Among them, about half consist entirely of preplanned speech, such as dialogues from plays, drama series, news broadcasts, and public speeches; three contain a mixture of both preplanned and spontaneous speech; only four are composed of spontaneous speech solely. Although data of structured speech are useful to researchers with interests in the phonetic and prosodic aspects of a language, spontaneous speech production captures phonetic variation, synchronic 
Table 1

Existing Spoken Chinese Corpora

\begin{tabular}{|c|c|c|}
\hline Title or Author(s) & Language & Content \\
\hline 1. Modern Chinese Language Corpus & Mandarin & $\begin{array}{l}\text { orthographically transcribed dialogues and monologues in plays and } \\
\text { recordings of speeches and humorous talk shows }\end{array}$ \\
\hline 2. Corpus of Chinese Phonology & Mandarin & recordings of 45,000 words, separate sentences, short passages, and dialogues \\
\hline 3. Pu3 Tong1 Hua4 & Mandarin & $\begin{array}{l}\text { standard pronunciation of } 1,275 \text { syllables by } 15 \text { male speakers and } \\
3,300 \text { bisyllabic words by one male speaker }\end{array}$ \\
\hline $\begin{array}{l}\text { 4. A database being compiled by the } \\
\text { Language Research Institute of the } \\
\text { Shanghai Normal University }\end{array}$ & Wu dialect & $\begin{array}{l}\text { recordings of samples collected in } 29 \text { districts in Zhejiang province and } \\
\text { the Shanghai area }\end{array}$ \\
\hline $\begin{array}{l}\text { 5. A spoken Chinese corpus being compiled } \\
\text { by the Language Research Institute of the } \\
\text { Chinese Academy of Social Sciences }\end{array}$ & Mandarin & $\begin{array}{l}\text { ultimately } 1,000 \mathrm{~h} \text { of recordings of "situated" discourse and speeches, } \\
50-100 \mathrm{~h} \text { of which will be transcribed and annotated }\end{array}$ \\
\hline 6. Spoken Beijing Accent Corpus & Mandarin & two million words of running talks and monologues \\
\hline 7. Linguistic Data Consortium & Mandarin & a collection of telephone conversations \\
\hline $\begin{array}{l}\text { 8. Chou and Tzeng (1999), } \\
\text { Tseng and Chou (1999) }\end{array}$ & Mandarin & 600 short paragraphs recorded by three male and three female speakers \\
\hline $\begin{array}{l}\text { 9. Mandarin Spoken Document } \\
\text { Retrieval project }\end{array}$ & Mandarin & $\begin{array}{l}\text { multimedia documents, including broadcasts, television and video programs, } \\
\text { films, songs, and music for retrieval by sound processing }\end{array}$ \\
\hline 10. Tse, Tang, Shi, and Li (1991) & Mandarin & transcriptions of speech of Taiwanese children \\
\hline 11. Tardif (1993) & Mandarin & transcriptions of utterances of children in Beijing \\
\hline 12. Fok (1974) & Cantonese & $\begin{array}{l}\text { recordings of } 1 \mathrm{~h} \text { of speech, including } 15 \mathrm{~min} \text { of a radio sample and } \\
45 \mathrm{~min} \text { of ordinary conversation, totaling } 13,068 \text { words }\end{array}$ \\
\hline 13. So (1992) & Cantonese & $\begin{array}{l}\text { approximately } 1,800 \text { syllables, with each syllable pronounced by several } \\
\text { native speakers in Hong Kong }\end{array}$ \\
\hline 14. Xu and Lee (1998) & $\begin{array}{l}\text { Shanghainese, } \\
\text { Cantonese, and } \\
\text { Mandarin }\end{array}$ & $\begin{array}{l}\text { transcriptions of recordings of plays, television shows, news broadcasts, and } \\
\text { some unstructured interviews }\end{array}$ \\
\hline 15. Lee and Wong (1998) & Cantonese & $\begin{array}{l}\text { longitudinal data of speech of children in Hong Kong, part of the } \\
\text { Child Language Data Exchange System (CHILDES) }\end{array}$ \\
\hline $\begin{array}{l}\text { 16. Fletcher, Leung, Stokes, } \\
\text { \& Weizman (2000) }\end{array}$ & Cantonese & cross-sectional data from 72 children in Hong Kong, part of CHILDES \\
\hline $\begin{array}{l}\text { 17. Hong Kong Cantonese Adult Language } \\
\text { Corpus (HKCAC) }\end{array}$ & Cantonese & $\begin{array}{l}\text { orthographic and phonetic transcriptions of } 8 \text { hours of recordings of various } \\
\text { phone-in programs and forums on radio stations in Hong Kong }\end{array}$ \\
\hline
\end{tabular}

sound change, false starts, repetitions, pauses, and speech errors. Of the four Cantonese databases comprising naturally occurring speech samples, Lee and Wong (1998) and Fletcher, Leung, Stokes, and Weizman (2000) are corpora of child language. Although Fok (1974) is an adult language database, it was developed about 30 years ago for the purpose of conducting a perceptual analysis of tones in Cantonese. Moreover, it contained only $1 \mathrm{~h}$ of speech and was transcribed into tones by ear. In other words, only the corpus by Leung and Law (2001) contains detailed phonetic transcriptions ${ }^{2}$ that allow frequency counts of different phonological units to be extracted. Since the information on type and token frequencies of various subsyllabic units reported below is derived from the HKCAC, a brief description of its key features is in order.

The HKCAC is based on more than $8 \mathrm{~h}$ of recordings of phone-in programs and forums on the radio in Hong Kong. The database represents the speech of a total of 69 native speakers, in addition to the program hosts. It has more than 140,000 syllable-character units. The recordings are transcribed both phonetically and orthographically. The two sets of transcriptions are linked to allow for crossreferencing. The datafiles are structured in such a way that a search engine specifically written for the database enables the user to search for information at the single syllable-character level and at the utterance level. For the former, one may obtain frequency counts of syllables and characters, the various phonetic realizations of a particular character with corresponding frequencies, and the set of characters associated with a particular syllable with their respective frequencies. For the latter, one may type in a character or syllable string and look up its occurrence in the corpus. The results are displayed in KWAL (key word and line) format, and the user may refer to the context in which the string appears for each occurrence.

\section{Type and Token Frequencies of Cantonese Tones, Onsets, Rimes, and Syllables}

Cantonese phonological system. The phonological system of Cantonese presented here draws on Bauer and Benedict (1997), which is one of the most up to date and comprehensive descriptions of contemporary Cantonese phonology. Cantonese is a tone language in which tone is used to distinguish lexical items. It contrasts with prosody/ intonation in that whereas tone is local and lexical, intonation is nonlexical and global. Hong Kong Cantonese has 
six distinct tones; T1 (high level, or 55), T2 (high rising, or 25), T3 (mid-level, or 33), T4 (mid-low falling, or 21), T5 (mid-low rising, or 23), and T6 (mid-low level, or 22). There are three entering tones that are carried by syllables ending on a stop consonant and correspond in height to the high level (T1), mid-level (T3), and mid-low level tones (T6).

The Cantonese syllable is traditionally analyzed into onset and rime. The inventory of onsets contain 19 phonemes - that is, [p, $\mathrm{p}^{\mathrm{h}}, \mathrm{t}, \mathrm{t}^{\mathrm{h}}, \mathrm{k}, \mathrm{k}^{\mathrm{h}}, \mathrm{kw}, \mathrm{kw}$ h $, \mathrm{m}, \mathrm{n}, \mathrm{y}, \mathrm{f}, \mathrm{s}$, $\mathrm{h}, \mathrm{ts}, \mathrm{ts} \mathrm{h}, \mathrm{w}, \mathrm{l}, \mathrm{j}]$ - distinguished in terms of five places of articulation (labial, dental/alveolar, palatal, velar, and glottal) and five manners of articulation (stop, fricative, affricate, nasal, and glide). The stop and affricate consonants are contrasted by aspiration, and not by voicing. Two of the nasal consonants, [m, $\mathrm{y}]$, can be syllabic. That is, they may occur alone as separate syllables [m, $\mathfrak{p}]$. Phonetically, there are three onsets $\left[\int, \mathrm{t} \int, \mathrm{t} \mathrm{h}^{\mathrm{h}}\right]$, which are palatalized allophones of $/ \mathrm{s}, \mathrm{ts}, \mathrm{ts} \mathrm{h} /$, respectively, occurring before rounded vowels. The standard set of Cantonese rimes has 53 members belonging to three types consisting of (1) a nuclear vowel [i, y, $\varepsilon, \mathbb{E}, \mathrm{a}, \mathrm{u}, \mathrm{\jmath}],{ }^{3}$ (2) a dipthong [iu, ei, øy, ei, eu, ai, au, ui, ou, oi], or (3) a vowel plus a final consonant [p, t, k, m, n, p]. Bauer and Benedict (1997) included three more rimes that occur in colloquial words, [عu, $\varepsilon \mathrm{m}, \varepsilon \mathrm{en}$.

A total of 750 distinctive syllables (regardless of tone) are recognized in Bauer and Benedict (1997) that are combinations of the 19 onsets and 56 rimes. This Cantonese syllabary includes 584 syllables representing standard Chinese characters, 126 colloquial syllables with no standard written forms (e.g., [leu2] 'to stir'), and 40 syllables representing English loanwords (e.g., movie [mul fi2]).

Extraction of frequency information from the HKCAC. The HKCAC contains two groups of database files in FileMarker 4.0 format (Leung \& Law, 2001). As was mentioned before, the utterance group subserves the utterance search functions, and the character group subserves the character search functions. A master file was created for each of the two groups of database files to perform the search query. The frequency information of different phonological units of spoken Cantonese was extracted from the character master file. Within the file, there was a syllable field containing syllable information in IPA (International Phonetic Alphabets) with segmental tone information. A program was written to mark and extract different syllables from the master file. A new database file with syllable, syllable without tone, onset, rime, tone, coda, and token count fields was then created. The extracted syllables, with segmental tone information, were then exported from the master file to the syllable field of this new file, in which each syllable appeared only once. A relation was set up between this new database file and the master file by linking their syllable fields. Through this relation, the frequency of occurrence of each syllable listed in the new file can be computed by referring to their individual occurrence in the master file. The frequency count of each syllable was imported into the token count field of the new file. Another program was written to extract the syllable without tone, onset, rime, coda, and tone from each of the records in the syllable field of the new file. The extracted information was then placed into the corresponding syllable without tone, rime, coda, and tone fields of the respective record. Finally, the type and token frequencies of different onsets, rimes, codas, and tones were obtained by setting different search criteria and by sorting the respective fields in the new file.

Comparisons between HKCAC and Fok (1974) and Bauer and Benedict (1997). Since the phonetic transcription of the HKCAC was based on connected speech and was intended to capture phonological phenomena, such as sound change, assimilation, contraction, and speech errors, one may expect to find phonological units of different sizes that do not appear in the Cantonese phonological system containing solely standard forms. To illustrate this situation, comparisons are made between information obtained from the HKCAC and that from previous studiesin particular, Fok (1974) for frequency counts of tones and Bauer and Benedict (1997) for inventories of rimes and syllables. Before calculating the frequency information, we first examined the type and token frequencies of all the syllables (regardless of tone) in the HKCAC and eliminated those that (1) had the same number of type and token counts, with (2) both counts being $\leq 3$, and (3) were not standard rimes. This was to remove "unusual" syllables resulting from speech errors. Using these criteria, we deleted 2,326 syllables, accounting for $1.62 \%$ of the corpus. The reduced database consisted of 141,149 syllables representing 1,923 different syllables. It then formed the basis of computation of tone, onset, rime, and syllable frequencies.

Table 2 provides the type and token frequencies of Cantonese tones. The distribution of tones is further divided in terms of the presence or absence of a coda and the identity of the coda. Differing from standard descriptions of Cantonese tones, we recognize a glottal stop coda [?] with no discernible place of articulation, and high rising, midlow rising and mid-low falling tones carried by syllables ending on a stop consonant $[\mathrm{p}, \mathrm{t}, \mathrm{k}]$. The occurrence of these tones is mostly the result of changed tone or interaction between tone and intonation in connected speech. A rough comparison of token frequencies between Table 2 and Fok (1974) reveals more similarities than differences between the two databases, as is shown in Table 3. Fok made several observations: (1) The falling tones, the rising tones, and the level tones occurred at almost identical frequencies; (2) the high tones appeared slightly more frequently than the low tones for the falling tones and the rising tones, but the opposite pattern was found for the level tones; and (3) T7 had a higher frequency than T9, which in turn appeared slightly more frequently than T8. Generally speaking, Observations 2 and 3 are also found in the HKCAC, with the differences between $\mathrm{T} 3$ and $\mathrm{T} 6$ and between T7 and T9 being smaller than those reported in Fok. The two sources seem to differ somewhat with respect to the distribution of tones across tone groups. The level tones $(34.65 \%)$ in the HKCAC seem to be more frequent 
Table 2

Type and Token Frequencies of Cantonese Tones by Codas

\begin{tabular}{|c|c|c|c|c|c|c|c|}
\hline Coda & $\begin{array}{c}\text { T1 } \\
\text { (High Level) }\end{array}$ & $\begin{array}{c}\mathrm{T} 2 \\
\text { (High Rising) }\end{array}$ & $\begin{array}{c}\text { T3 } \\
\text { (Mid-Level) }\end{array}$ & $\begin{array}{c}\text { T4 } \\
\text { (Mid-Low Falling) }\end{array}$ & $\begin{array}{c}\text { T5 } \\
\text { (Mid-Low Rising) }\end{array}$ & $\begin{array}{c}\text { T6 } \\
\text { (Mid-Low Level) }\end{array}$ & Total \\
\hline \multicolumn{8}{|c|}{ Token Frequencies of Tones by Codas } \\
\hline No coda & 16,813 & 14,204 & 20,702 & 9,299 & 14,248 & 20,387 & 95,653 \\
\hline $\mathrm{m}$ & 1,278 & 4,238 & 404 & 360 & 24 & 209 & 6,513 \\
\hline $\mathrm{n}$ & 3,152 & 1,691 & 1,405 & 3,094 & 310 & 2,548 & 12,200 \\
\hline $\mathrm{y}$ & 3,950 & 3,146 & 1,182 & 3,116 & 511 & 2,074 & 13,979 \\
\hline Subtotal & 25,193 & 23,279 & 23,693 & 15,869 & 15,093 & 25,218 & 128,345 \\
\hline $\mathrm{p}$ & 64 & 15 & 159 & 0 & 0 & 641 & 879 \\
\hline $\mathrm{t}$ & 2,781 & 25 & 1,089 & 9 & 0 & 1,507 & 5,411 \\
\hline $\mathrm{k}$ & 2,103 & 27 & 2,059 & 20 & 5 & 2,289 & 6,503 \\
\hline ? & 4 & & 2 & & & 5 & \\
\hline Subtotal & 4,952 & 67 & 3309 & 29 & 5 & 4442 & 12,804 \\
\hline Total & 30,145 & 23,346 & 27,002 & 15,898 & 15,098 & 29,660 & 141,149 \\
\hline \multicolumn{8}{|c|}{ Type Frequencies of Tones by Codas } \\
\hline No coda & 177 & 170 & 189 & 130 & 98 & 149 & 913 \\
\hline $\mathrm{m}$ & 26 & 26 & 14 & 18 & 4 & 12 & 100 \\
\hline $\mathrm{n}$ & 73 & 56 & 42 & 49 & 18 & 51 & 289 \\
\hline y & 74 & 49 & 42 & 67 & 19 & 45 & 296 \\
\hline Subtotal & 350 & 301 & 287 & 264 & 139 & 257 & 1,598 \\
\hline $\mathrm{p}$ & 9 & 3 & 13 & 0 & 0 & 16 & 41 \\
\hline $\mathrm{t}$ & 34 & 3 & 48 & 3 & 0 & 35 & 123 \\
\hline $\mathrm{k}$ & 47 & 3 & 50 & 4 & 1 & 52 & 157 \\
\hline$?$ & 2 & & 1 & & & 1 & \\
\hline Subtotal & 92 & 9 & 112 & 7 & 1 & 104 & 325 \\
\hline Total & 442 & 310 & 399 & 271 & 140 & 361 & 1,923 \\
\hline
\end{tabular}

than the falling tones $(29.09 \%)$, which are slightly more frequent than the rising tones (27.19\%). Given that our corpus is 10 times the size of that in Fok, the relative frequencies across tone groups found in the HKCAC are more likely to accurately reflect the frequency of occurrence of tones in natural speech.

The onset inventory shown in Table 4 contains 19 phonemes and three palatalized allophones $\left[\int, \mathrm{t} \int, \mathrm{t} \int^{\mathrm{h}}\right]$. There are 11 coronals (dental/alveolar and palatal), five labials, five velars, and one glottal. Not surprisingly, coro-

Table 3 Comparison Between HKCAC and Fok (1974)

\begin{tabular}{ccc}
\hline Tone & HKCAC & Fok $(1974)$ \\
\hline Falling & & \\
T1* & $25,193(17.85 \%)$ & $2,239(17.1 \%)$ \\
T4 & $15,869(11.24 \%)$ & $1,599(12.2 \%)$ \\
Total & $41,062(29.09 \%)$ & $3,838(29.3 \%)$ \\
Rising & & \\
T2 & $23,279(16.49 \%)$ & $2,530(19.4 \%)$ \\
T5 & $15,093(10.69 \%)$ & $1,476(11.3 \%)$ \\
Total & $38,372(27.19 \%)$ & $4,006(30.7 \%)$ \\
Level & & \\
T3 & $23,693(16.79 \%)$ & $1,874(14.3 \%)$ \\
T6 & $25,218(17.87 \%)$ & $2,149(16.4 \%)$ \\
Total & $48,911(34.65 \%)$ & $4,023(30.7 \%)$ \\
Entering $\dagger$ & & \\
T7 & $4,952(3.51 \%)$ & $596(4.6 \%)$ \\
T8 & $3,309(2.34 \%)$ & $261(2 \%)$ \\
T9 & $4,442(3.15 \%)$ & $344(2.6 \%)$ \\
\hline
\end{tabular}

*T1 was a high falling tone in Fok (1974). †Entering tones are tones occurring on syllables with a stop consonant coda; T7, T8, and T9 in Fok correspond to T1, T3, and T6, respectively, of syllables with a $[\mathrm{p}, \mathrm{t}, \mathrm{k}]$ coda in the HKCAC. nal consonants are the most frequent $(54.09 \%)$, followed by velars $(20.78 \%)$, labials ( $14.83 \%)$, and the glottal sound $(10.29 \%)$. As for manner of articulation, the eight stop consonants account for $33.24 \%$ of all the onsets in the corpus, followed by the three glides $(25.33 \%)$, the four fricatives $(19.95 \%)$, the four affricates $(12.21 \%)$, and the three nasals $(9.26 \%)$. We also note that for the stop and affricate consonants, the unaspirated sounds are far more frequent than their aspirated counterpart $(34,205$ vs. 6,949$)$. Among the nasal consonants, $[\mathrm{m}]$ is the most frequent as an onset but the least frequent as a coda (see Table 2).

Sixty-nine rimes are identified in the HKCAC, as presented in Table 5, as compared with 56 in Bauer and Benedict (1997). The 13 additional rimes result from various phonological processes mostly related to connected speech, including vowel destressing [ə, əm, ət, ək], coda deletion $[\mathrm{e}]$, assimilation to the onset of the following syllable [øn, om, um], and contemporary sound change, including alveolarization [œn] and glottalization of stop codas [ə?, a?, $\mathrm{e}$, o?]. Although there are fewer different types of rimes without a coda (i.e., open syllables) than closed syllables $(913$ vs. 1,010$)$, open syllables are twice as frequent (67.77\% vs. $32.23 \%)$.

A Cantonese syllabary derived from the HKCAC has been compiled. ${ }^{4}$ It consists of 753 syllables (regardless of tone). Recall that the syllabary in Bauer and Benedict (1997) recognizes 750 syllables, including 584 standard syllables, 126 colloquial syllables, and 40 syllables related to English loanwords. Given that the HKCAC is based on connected speech, whereas Bauer and Benedict's syllabary is concerned with citation forms, it would be interesting to compare the two inventories. 
Table 4

Token (and Type) Frequencies of Onsets

\begin{tabular}{|c|c|c|c|c|c|}
\hline & Labial & Dental/Alveolar & Palatal & Velar & Glottal \\
\hline Stop & $\begin{array}{l}{[\mathrm{p}] 3,175(77)} \\
{\left[\mathrm{p}^{\mathrm{h}}\right] 948(50)}\end{array}$ & $\begin{array}{l}{[\mathrm{t}] 11,205(125)} \\
{\left[\mathrm{t}^{\mathrm{h}}\right] 2,882(68)}\end{array}$ & & $\begin{array}{l}{[\mathrm{k}] 19,319(136)} \\
{\left[\mathrm{k}^{\mathrm{h}}\right] 3,044(54)} \\
{[\mathrm{kw}] 506(20)} \\
{[\mathrm{kwH}] 75(10)}\end{array}$ & \\
\hline $\begin{array}{l}\text { Fricative } \\
\text { Affricate }\end{array}$ & [f] $3,073(61)$ & $\begin{array}{l}\text { [s] 8,744 (136) } \\
{[\mathrm{ts}] 11,564(140)} \\
{\left[\mathrm{ts}^{\mathrm{h}}\right] 3,274(102)}\end{array}$ & $\begin{array}{l}{\left[\int\right] 139(18)} \\
{\left[t \int\right] 200(30)} \\
{\left[t \int h\right] 86(19)}\end{array}$ & & [h] $12,738(119)$ \\
\hline $\begin{array}{l}\text { Nasal } \\
\text { Glide }\end{array}$ & $\begin{array}{l}{[\mathrm{m}] 6,711(119)} \\
{[\mathrm{w}] 4,462(75)}\end{array}$ & $\begin{array}{l}{[\mathrm{n}] 1,970(59)} \\
{[1] 13,535(140)}\end{array}$ & [j] 13,368 (125) & [y] 2789 (77) & \\
\hline
\end{tabular}

The comparison showed 148 syllables listed in Bauer and Benedict (1997) that do not appear in the HKCAC; conversely, 154 syllables that occur in the HKCAC are not included in Bauer and Benedict's syllabary. The former group comprises 79 colloquial syllables, 23 syllables in loanwords, and 46 standard syllables. Several reasons may account for the absence of the standard syllables in the HKCAC. Although Bauer and Benedict recognize the distinction between [n] and [1] in the onset position, few Hong Kong Cantonese speakers still contrast the two. This contemporary sound change accounts for 10 of the missing syllables. There are 5 syllables with a type frequency of 1 that are associated with formal speech (i.e., [nek], [mik], [hit], [hiu], and $\left.\left[\mathrm{k}^{\mathrm{h}} \mathrm{cEk}\right]\right)$; hence, they were not found in the casual conversations of the HKCAC. The third reason has to do with the occurrence of the palatalized $\left[\int, \mathrm{t} \int, \mathrm{t} \int^{\mathrm{h}}\right]$. In the HKCAC, the two series [s, ts, tsh] and $\left[\int, \mathrm{t} \int, \mathrm{t} \int^{\mathrm{h}}\right]$ are in free variation before rounded vowels, whereas Bauer and Benedict consider them in complementary distribution. This difference further explains the absence of 13 syllables. In short, only 18 standard syllables cannot be accounted for in terms of the ways in which the two syllabaries were compiled. It is worth noting that 12 of the 18 syllables have a stop coda [p, t, $\mathrm{k}$ ]. This is not surprising in light of the fact that syllables with a stop coda can carry only one of three tones (T1, T3, or T6), which naturally reduces their probability of occurrence in speech.

Regarding the 154 syllables identified in the HKCAC but not found in the Bauer and Benedict (1997) syllabary, we have already mentioned some of the reasons in the discussion of the rime list. We note that vowel destressing (i.e., syllables containing [ə]) accounts for 21 of the syllables, coda deletion (i.e., open syllables containing [e]) for 9 cases, assimilation of the coda to the onset of the following syllable in place of articulation for 15 absent syllables, alveolarization for 19 instances, and glottalization of the coda for 6 cases. In addition, several other factors have contributed to the discrepancy, including (1) the difference between the two syllabaries in the treatment of the two onset series, $\left[\mathrm{s}, \mathrm{ts}, \mathrm{ts}^{\mathrm{h}}\right]$ and $\left[\int, \mathrm{t} \int, \mathrm{t} \int^{\mathrm{h}}\right]$, which explains

Table 5

Token (and Type) Frequencies of Rimes

\begin{tabular}{|c|c|c|c|c|c|c|c|c|}
\hline & No Coda & $\mathrm{m}$ & $\mathrm{n}$ & $\mathrm{y}$ & $\mathrm{p}$ & $\mathrm{t}$ & $\mathrm{k}$ & $?$ \\
\hline$\partial$ & $5,585(73)$ & $3(1)$ & & & & $5(2)$ & $315(7)$ & $2(1)$ \\
\hline $\mathrm{a}$ & $8,171(77)$ & 768 (22) & 2,189 (57) & 225 (19) & $169(12)$ & 740 (24) & $1,360(34)$ & $7(2)$ \\
\hline $\mathrm{e}$ & 48 (4) & $4,887(42)$ & $4,340(61)$ & $1,127(30)$ & $527(19)$ & $3,341(36)$ & $1,245(20)$ & $4(2)$ \\
\hline$\varepsilon$ & $6,816(51)$ & $16(2)$ & $25(5)$ & $586(26)$ & & $14(3)$ & 237 (13) & \\
\hline$\varnothing$ & & & $444(20)$ & $7(2)$ & & $442(7)$ & & \\
\hline i & $9,302(54)$ & 767 (27) & $3,042(51)$ & $3,528(53)$ & $183(10)$ & $403(20)$ & 1,079 (19) & \\
\hline 0 & $13,764(79)$ & & $220(18)$ & $2,590(51)$ & & $46(6)$ & $1,320(28)$ & $3(1)$ \\
\hline$œ$ & $103(20)$ & & $86(16)$ & $2,895(48)$ & & & $127(8)$ & \\
\hline o & & $70(5)$ & & $2,980(62)$ & & & $820(28)$ & \\
\hline $\mathrm{u}$ & $851(21)$ & $2(1)$ & $572(20)$ & & & $108(13)$ & & \\
\hline $\mathrm{y}$ & $1,565(35)$ & & $1,319(44)$ & $4(2)$ & & $312(12)$ & & \\
\hline ai & $2,218(47)$ & & & & & & & \\
\hline au & $604(32)$ & & & & & & & \\
\hline ei & $11,151(72)$ & & & & & & & \\
\hline $\mathrm{eu}$ & $6,074(59)$ & & & & & & & \\
\hline ei & $8,581(60)$ & & & & & & & \\
\hline$\varnothing y$ & $4,876(53)$ & & & & & & & \\
\hline$\varepsilon u$ & $7(1)$ & & & & & & & \\
\hline iu & $1,726(40)$ & & & & & & & \\
\hline ou & $7,842(63)$ & & & & & & & \\
\hline oi & $1,610(39)$ & & & & & & & \\
\hline ui & $1,089(23)$ & & & & & & & \\
\hline
\end{tabular}


the presence of a total of 43 syllables in HKCAC, (2) zero onset in 23 syllables occurring quite frequently in fast connected speech (e.g., [mou løn] $\rightarrow$ [mou øn], [kə ti] $\rightarrow$ [ko i], [li jœy] $\rightarrow$ [li œn]), (3) assimilation of the onset to the coda of the preceding syllable (e.g., the final particle [lak] can be realized as [nak] in the context [tshin nak]), which accounts for 14 cases, (4) influence from another dialect for 3 syllables (i.e., [tou 1] meaning "also" $\rightarrow$ [tut 7] or [tui ]], [phei $\dashv$ jy $V$ ] meaning "for example" $\rightarrow$ $\left.\left[\mathrm{p}^{\mathrm{h}} \varnothing \mathrm{y} \dashv \mathrm{y} \vee\right]\right)$, and (5) one syllable resulting from contraction of two syllables (e.g., [m yam] "not correct" $\rightarrow$ [mam]).

\section{Conclusion}

This article marks the first report on type and token frequencies of tones, onsets, codas, rimes, and syllables in Hong Kong Cantonese extracted from a spoken corpus. Comparisons between the inventories of the various phonological units provided here and those of previous relevant references illustrate how such information based on connected speech may differ from standard descriptions of the Cantonese phonological system. Although the HKCAC is a relatively small database, it is believed that the frequency information derived from it will nevertheless benefit future research in this language.

\section{REFERENCES}

BAUER, R. S., \& Benedict, P. K. (1997). Modern Cantonese phonology. New York: Mouton de Gruyter.

Chou, F.-C., \& TsEng, C.-Y. (1999). The design of prosodically oriented Mandarin speech database. Proceedings of the 17th International Congress of Phonetic Sciences, 3, 2375-2377.

Fletcher, P., Leung, C.-S. S., Stokes, S., \& Weizman, Z. (2000). Cantonese pre-school language development: A guide (Report of the project "Milestones in the learning of spoken Cantonese by pre-school Children"). Hong Kong: Language Fund.

FOK, Y. Y. (1974). A perceptual study of tones in Cantonese. Hong Kong: Centre of Asian Studies, University of Hong Kong.

Lee, T., \& Wong, C. (1998). CANCORP: The Hong Kong Cantonese child language corpus. Cahiers de Linguistique: Asie Orientale, 27, 211-228.

Leung, M.-T., \& LAW, S.-P. (2001). HKCAC: The Hong Kong Cantonese adult language corpus. International Journal of Corpus Linguistics, 6, 305-326.

Robson, J., Pring, T., Marshall, J., \& Chiat, S. (2003). Phoneme frequency effects in jargon aphasia: A phonological investigation of nonword errors. Brain \& Language, 85, 109-124.

So, L. K. H. (1992). Hong Kong spoken Cantonese database. Hong Kong: Research Grant Council.

TARDIF, T. (1993). Adult-to-child speech and language acquisition in Mandarin Chinese. Unpublished doctoral dissertation, Yale Univeristy

TsE, J. K.-P., TANG, T.-C., SHI, Y., \& Li, E. (1991). Chinese children's language acquisition and development (National Science Council Research Report). National Taiwan Normal University, Taiwan: Department of English.

TsenG, C.-Y., \& Chou, F.-C. (1999). A prosodic labeling system for Mandarin speech database. Proceedings of the 17th International Congress of Phonetic Sciences, 3, 2379-2382.

WANG, J. (2001). Recent progress in corpus linguistics in China. International Journal of Corpus Linguistics, 6, 281-304.

Xu, L.-J., \& LEe, T. (1998). Parametric variation in three Chinese dialects, Cantonese, Shanghainese and Mandarin. Hong Kong: Research Grant Council.
ZANGWILL, O. L. (1975). A phonological investigation of aphasic speech Linguistics, 154-155, 163-164.

ZEE, E. (1998). Resonance frequencies and transcription of the vowels in Cantonese. In Proceedings of the 10th North American Conference on Chinese Linguistics and the 7th Annual Meeting of the International Association of Chinese Linguistics (pp. 90-97). Stanford.

ZEE, E. (1999). An acoustic analysis of the diphthongs in Cantonese. In Proceedings of the 14th International Congress of Phonetic Sciences (pp. 1101-1104). San Francisco.

\section{NOTES}

1. The term Hong Kong Cantonese refers to the variety of Cantonese that is spoken in Hong Kong. It is similar to the form of Cantonese spoken in Guganzhou, the capital of neighbouring Guangdong province in mainland China.

2. The recordings in the database were transcribed by an individual with an undergraduate training in linguistics. All the phonetic transcriptions were double-checked by S.-P. Law or S.-Y. Fung for accuracy.

3. On the basis of measurements of formant frequencies, Zee (1998) proposed that the vowels should be transcribed with diacritic marks as

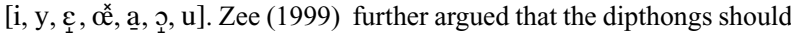
also be transcribed in a similar fashion. However, these proposals have not been adopted by mainstream Cantonese linguists.

4. Details of the syllabary can be found in the file leung2004t6.txt, contained in Leung-BRMIC-2004.zip, which is downloadable from http://www.psychonomic.org/archive/.

\section{ARCHIVED MATERIALS}

The following materials and links may be accessed through the Psychonomic Society's Norms, Stimuli, and Data archive, http://www. psychonomic.org/archive/.

To access these files or links, search the archive for this article using the journal (Behavior Research Methods, Instruments, \& Computers), the first author's name (Leung), and the publication year (2004).

FILE: Leung-BRMIC-2004.zip.

DESCRIPTION: The compressed archive file contains seven files:

leung2004t1.txt, containing a list of existing spoken Chinese corpora. Each row represents one of 17 data corpora; three columns represent title or author(s), language, and content, respectively.

leung2004t2.txt, containing type and token frequencies of Cantonese tones by codas. Each column represents one of six tones (high level, high rising, mid-level, mid-low falling, mid-low rising, and mid-low level), with the rightmost column being the total; the rows represent the codas.

leung2004t3.txt, containing a comparison of distribution of tones between HKCAC developed by Leung and Law (2001) and Fok (1974). The columns represent the two sources and the rows represent the tones.

leung2004t4.txt, containing token (and type) frequencies of onsets. Each column represents one of the places of articulation (labial, dental/alveolar, palatal, velar, and glottal); the rows represent the manners of articulation (stop, fricative, affricate, nasal, and glide).

leung2004t5.txt, containing token (and type) frequencies of rimes. Each row represents one of 22 nuclei; each column represents one of eight codas, including zero coda, [m, $\mathrm{n}, \mathrm{y}, \mathrm{p}, \mathrm{t}, \mathrm{k}, ?]$.

leung2004t6.txt, containing token (and type) frequencies of syllables. Each row represents a rime; each column represents an onset, including zero onset. The total number of occurrence of a syllable and its distribution over the six tones are given in each cell.

leung2004-6tables.pdf, containing information on all six tables in pdf format.

AUTHOR's E-MAIL ADDREss: mtleung@hkusua.hku.hk.

AUTHOR's WEB SITE: http://www.hku.hk/speech/research/aphasia-lab. htm.

(Manuscript received May 16, 2003; revision accepted for publication June 4, 2004.) 